\title{
A Feasible SIMS Study for Characterizing Ferric Oxyhydroxides Formed on the Iron Surface Using Deuterium
}

\author{
Shigeru Suzuki*, Yohei Takahashi and Yoshio Waseda \\ Institute of Multidisciplinary Research for Advanced Materials, Tohoku University, Sendai 980-8577, Japan
}

Secondary ion mass spectrometry (SIMS) has been applied to hydrogen and deuterium analysis for ferric oxyhydroxides, which is formed by reaction of an iron substrate with water; either $\mathrm{H}_{2} \mathrm{O}$ or $\mathrm{D}_{2} \mathrm{O}$ containing a small amount of sodium chloride. Mass spectra of positive and negative ions obtained by SIMS showed that deuterium in ferric oxyhydroxides can be differentiated from hydrogen, although many species of secondary ion peaks are detected. Mass spectra from an iron sample, which firstly reacted with $\mathrm{H}_{2} \mathrm{O}$, subsequently dried and finally reacted with $\mathrm{D}_{2} \mathrm{O}$, indicated that $\mathrm{D}_{2} \mathrm{O}$ reaches a reaction front of the iron substrate through ferric oxyhydroxides formed by reaction with $\mathrm{H}_{2} \mathrm{O}$. This implies that the ferric oxyhydroxides formed by reaction with $\mathrm{H}_{2} \mathrm{O}$ are, more or less, porous and thus water penetrates into ferric oxyhydroxides to the substrate. These results also suggest that SIMS analysis using isotopes enable us to characterize a formation process of ferric oxyhydroxides and permeability of foreign ions in the ferric oxyhydroxides.

(Received February 25, 2003; Accepted May 21, 2003)

Keywords: surface analysis, secondary ion mass spectrometry, $x$-ray photoelectron spectroscopy, surface reaction, ferric oxyhydroxides

\section{Introduction}

An oxide layer consisting of iron and oxygen is easily formed on the surface of iron and steel, when these metals are heated in air. ${ }^{1)}$ Secondary ion mass spectrometry (SIMS) spectra show many ion species emitted from the iron oxides, which are not only ions of single atoms but also cluster ions. ${ }^{2)}$ On the other hand, ferric oxyhydroxides, which are typical corrosion products of iron and steel, are also known to be formed on the iron surface, when it is exposed to humid air at about room temperature. The structure of ferric oxyhydroxides is described by a network structure of $\mathrm{FeO}_{6}$ octahedral units containing hydrogen. ${ }^{3)}$ As related to the structure, the elemental analysis is also required for obtaining information on a formation process of the ferric oxyhydroxides. For instance, ferric oxyhydroxides consists of not only iron and oxygen but also hydrogen, and hydrogen is considered to play an important role in their formation. Therefore, it is of great interest to analyze fragment ions consisting of iron, oxygen and hydrogen, because mass spectra of secondary ions from such ferric oxyhydroxides may include information on their composition and structure. This kind study has been carried out in structural characterization of polymers. ${ }^{4)}$ Furthermore, by replacing hydrogen with deuterium, that is an isotope of hydrogen, some additional information of ferric oxyhydroxides, a formation process of the ferric oxyhydroxides may be obtained.

Thus, the objective of this work is to obtain characteristic SIMS mass spectra from the iron surface, which reacts with water, that is $\mathrm{H}_{2} \mathrm{O}$ or $\mathrm{D}_{2} \mathrm{O}$, containing a small amount of salt. A feasible study was also carried out for obtaining fundamental information of a corrosion process by replacing hydrogen with deuterium in the reaction.

*Corresponding author: Email: ssuzuki@tagen.tohoku.ac.jp

\section{Experimental}

\subsection{Sample preparation}

An ingot of pure iron was made by vacuum melting, and it was rolled to $0.5 \mathrm{~mm}$ in thickness. The contents of main impurities in the ingot were 0.0007 mass $\%$ C, 0.005 mass $\%$ $\mathrm{Si},<0.0001$ mass $\% \mathrm{Mn}, 0.0006$ mass $\% \mathrm{P}$ and 0.0003 mass $\%$ $\mathrm{S}$. They were mechanically polished for analyzing a flat surface using SIMS. The sample prepared is referred to as Sample $\mathrm{F}$ hereafter.

A drip of $\mathrm{H}_{2} \mathrm{O}$ or $\mathrm{D}_{2} \mathrm{O}$ solution containing 2 mass $\%$ sodium chloride was dropped on the sample surface. Corrosion products of about fifty micrometers in thickness were formed on the sample surface at room temperature for about $8.6 \times 10^{4} \mathrm{~s}$. Since the corrosion products, which are mostly ferric oxyhydroxides, ${ }^{3)}$ are non-conductive, most of the corrosion products were mechanically removed close to the reaction front of the iron substrate by a pair of tweezers for SIMS measurements. The samples reacted with $\mathrm{H}_{2} \mathrm{O}$ and $\mathrm{D}_{2} \mathrm{O}$ are referred to as Sample $\mathrm{H}$ and Sample D, respectively.

In order to study a cyclic corrosion process of iron, the sample surface firstly reacted with $\mathrm{H}_{2} \mathrm{O}$ containing sodium chloride at room temperature for $8.6 \times 10^{4} \mathrm{~s}$, subsequently dried in air for $1.7 \times 10^{5} \mathrm{~s}$, and finally reacted with of $\mathrm{H}_{2} \mathrm{O}$ for $8.6 \times 10^{4} \mathrm{~s}$. SIMS measurements were performed in the sample surface, on which ferric oxyhydroxides were removed close to the reaction front. This sample is referred to as Sample HD.

\subsection{Measurements}

SIMS was used for analyzing ion species from ferric oxyhydroxides, which remain close to the reaction front of the iron substrate. SIMS measurements were carried out using PHI-6600 with quadrupole-type mass analyzer. The mass resolution of quadrupole-type analyzer is relatively low compared to the other type of analyzer, but it is enough to obtain information on a number of ion species in a wide mass range. An incident beam of $5.0 \mathrm{keV} \mathrm{Cs}^{+}$ions was irradiated to the sample surface, and positive and negative secondary 
ions were detected from the surface. Narrow mass spectra in low mass ranges were also studied, in order to find hydrogen and deuterium relevant ion species. Sputter depth profiling in SIMS is often useful for characterizing a layered structure of a flat surface. However, sputter depth profiles of ferric oxyhydroxides are not shown in this work, since they do not provide clear information. This is because a thick layer of ferric oxyhydroxides is non-conductive and heterogeneous, and the sample surface is not flat.

\section{Results and Discussion}

\subsection{Wide mass spectra by SIMS}

Figures 1(a) and (b) show wide mass spectra of positive ions and negative ions emitted from Sample F (pure iron), respectively. The mass spectra were measured after the sample was sputtered by about five micrometers in-depth, in order to remove contaminated and oxidized surface layer. However, the influence of oxygen and carbon on these mass spectra is detected, especially in the mass spectra of negative ions. Carbon relevant ions are likely to originate from carbon in the sample matrix, while oxygen relevant ions may be attributed to native oxides formed on the sample surface. Native oxides are produced by exposure to air. ${ }^{5)}$ Iron ions $\left({ }^{54} \mathrm{Fe},{ }^{56} \mathrm{Fe}\right.$ and $\left.{ }^{57} \mathrm{Fe}\right)$ and iron cluster ions $\left({ }^{112} \mathrm{Fe}_{2}^{+},{ }^{189} \mathrm{CsFe}^{+}\right)$ are dominant in the mass spectra of positive ions, whereas
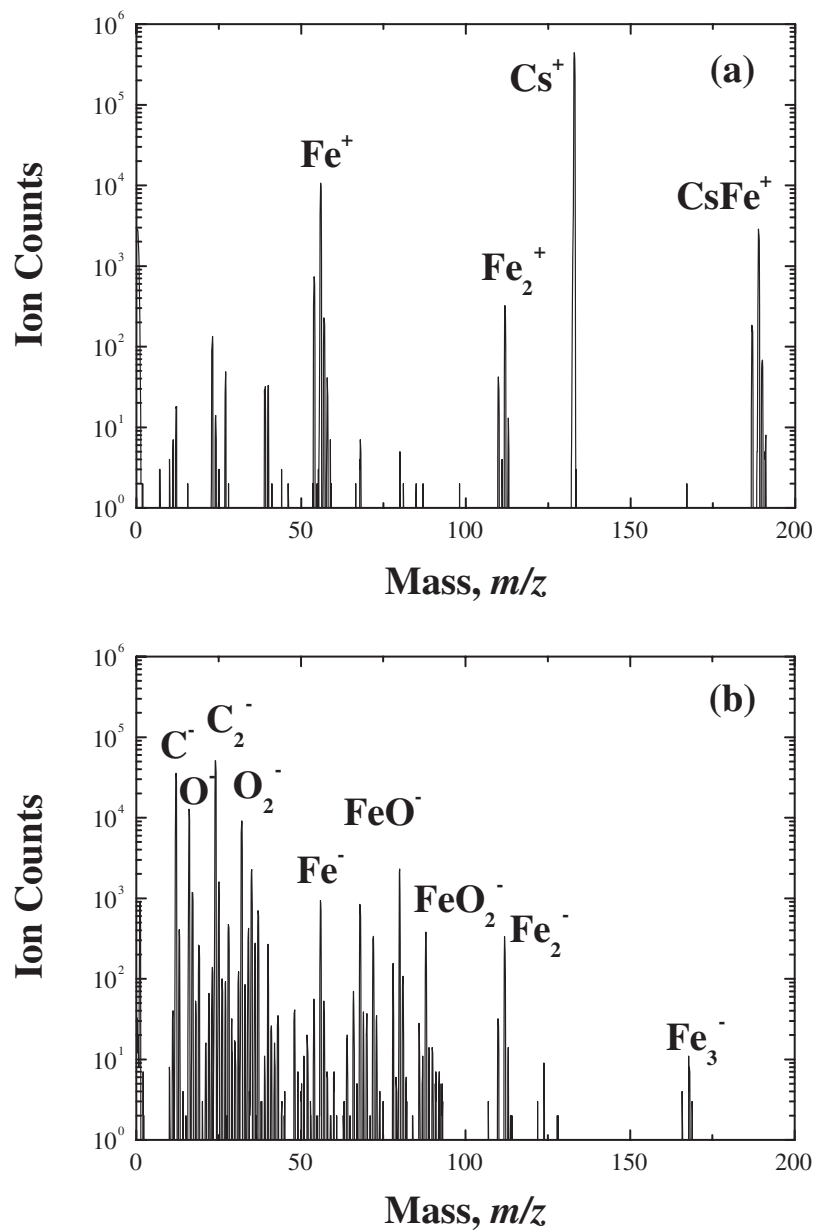

Fig. 1 Wide mass spectra of (a) positive ions and (b) negative ions from Sample F. oxygen and carbon relevant ions are sensitive in the mass spectra of negative ions.

Figures 2(a) and (b) provide wide mass spectra of positive ions and negative ions from Sample $\mathrm{H}$, which is mainly ferric oxyhydroxides formed by reaction with $\mathrm{H}_{2} \mathrm{O}$. It is noted that counts of positive and negative ions from Sample $\mathrm{H}$ are much larger than those of Sample F, although measuring conditions in SIMS are almost constant. This phenomenon is attributed to the matrix effect, by which the production of secondary ions is varied, as observed in enhancement of secondary ions from oxides. ${ }^{6}$ A large number of sodium ions are also detected in these spectra, in addition to iron relevant ions observed in Sample F. The sodium ions originate from sodium chlorides in aqueous solution, which still remain on the sample surface after drying the sample. The large count of sodium ions means that the sensitivity of sodium is very high, since sodium is easily ionized. Large counts of sodium cluster ions are also observed in ${ }^{46} \mathrm{Na}^{+},{ }^{81}\left(\mathrm{Na}_{2} \mathrm{Cl}\right)^{+}$and ${ }^{82}\left(\mathrm{Na}_{2} \mathrm{Cl}\right)^{+}$in mass spectra of positive ions. On the other hand, many iron relevant ions are detected in the mass spectra of negative ions. These ions are likely to be fragment ions from ferric oxyhydroxides, of which the structure is composed of $\mathrm{FeO}_{6}$ octahedral units containing hydrogen. ${ }^{3)}$ Chlorine ions are also observed in the mass spectra of negative ions, since the electron affinity of chlorine ions is very large.
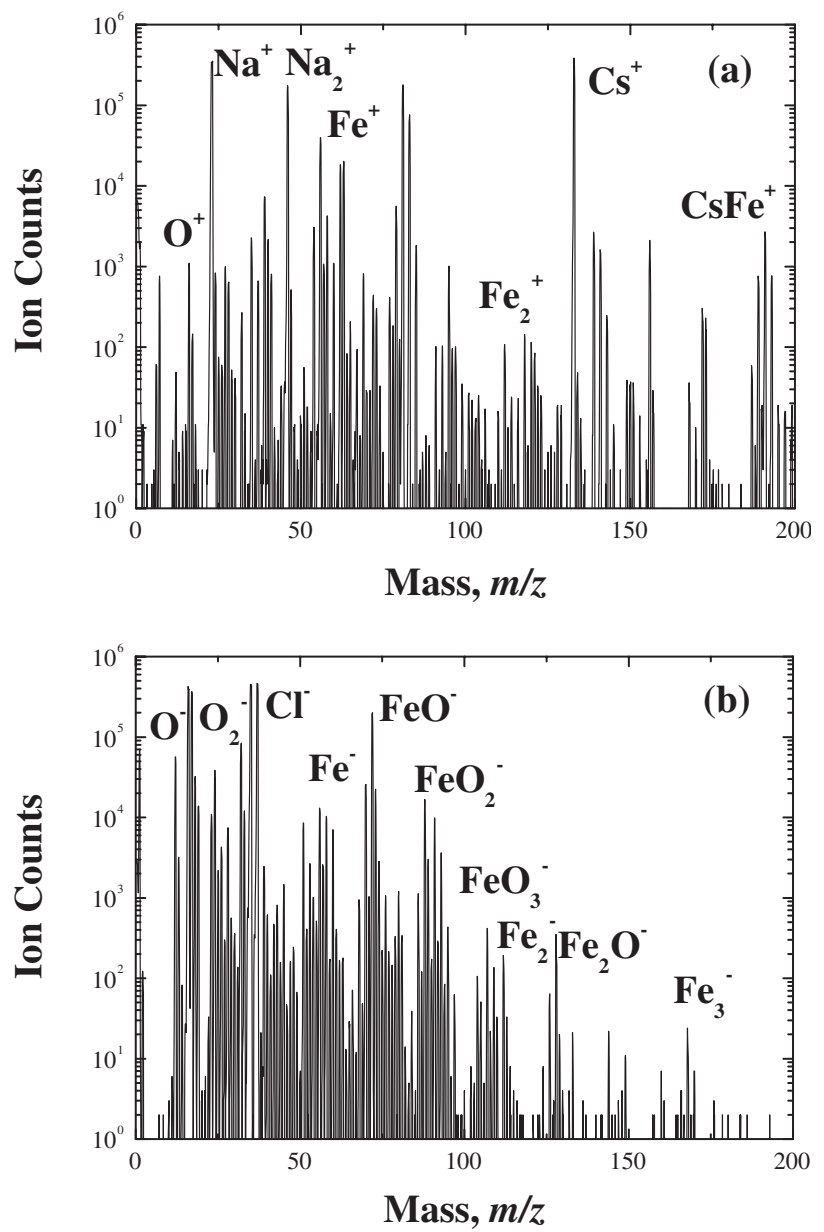

Fig. 2 Wide mass spectra of (a) positive ions and (b) negative ions from Sample H. 

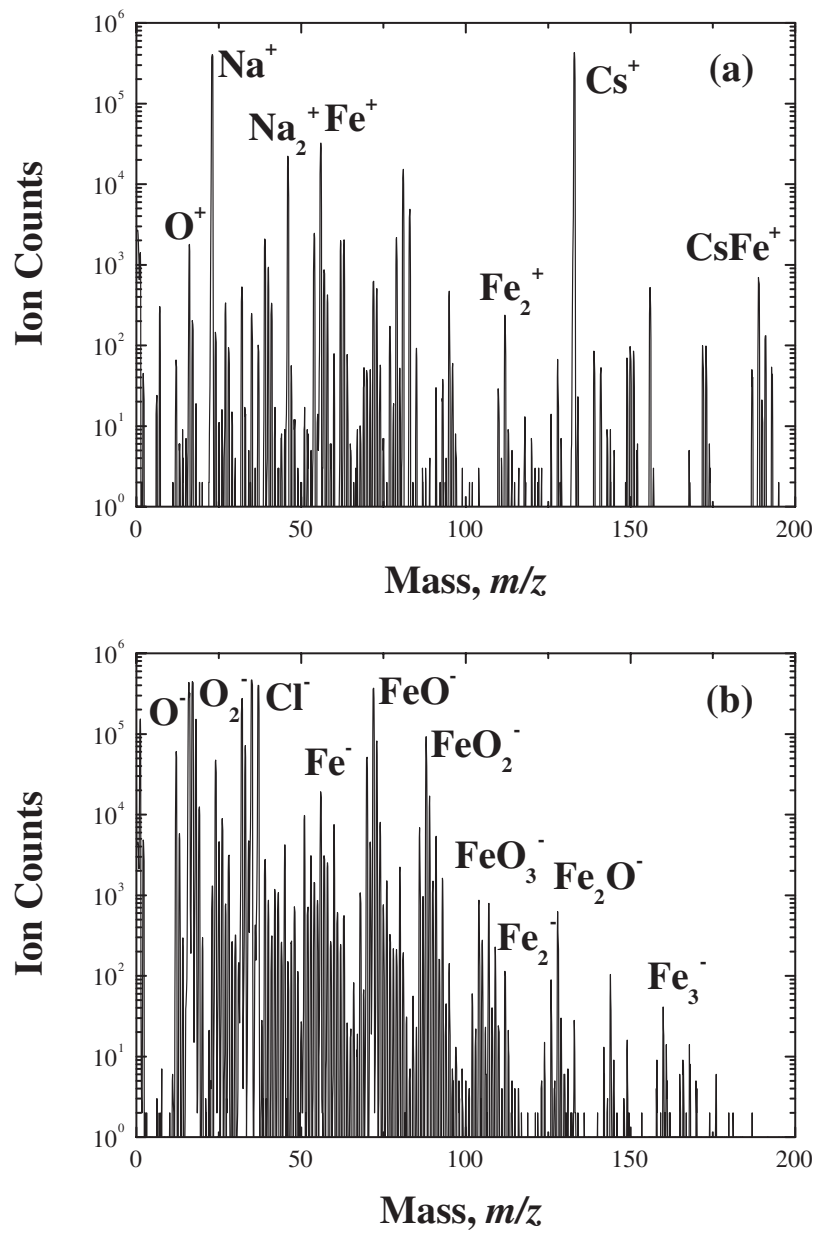

Fig. 3 Wide mass spectra of (a) positive ions and (b) negative ions from Sample D.

Wide mass spectra of positive ions and negative ions from Sample D, consisting mainly of ferric oxyhydroxides formed by reaction with $\mathrm{D}_{2} \mathrm{O}$, are shown in Figs. 3(a) and (b), respectively. Fundamental features of these mass spectra are similar to those for Sample H. Some differences are observed in counts of sodium and chlorine relevant ions between these two samples, but it may be attributed to differences of the amount of sodium chlorides and ferric oxyhydroxides on the sample surface. Significant difference between Sample H and Sample D is hardly observed in wide mass spectra, although different features will be found in a low mass range, as shown below.

\subsection{Narrow mass spectra by SIMS}

Figures 4(a), (b) and (c) show narrow mass spectra of positive ions form Sample H, Sample D and Sample HD, respectively. Absolute values of secondary ion counts are not likely to be compared among these data, since the amounts of ferric oxyhydroxides and sodium chlorides remaining on the sample surface are not constant in these samples. Therefore, the relative ion counts should be focused on finding a difference between mass spectra associated with hydrogen and deuterium. Ions of one in mass number may be attributed to residual hydrogen in the ultra-high vacuum analyzer and adsorbed hydrocarbon ${ }^{5)}$ as well as hydrogen in ferric oxyhydroxides, and ions of two in mass number are
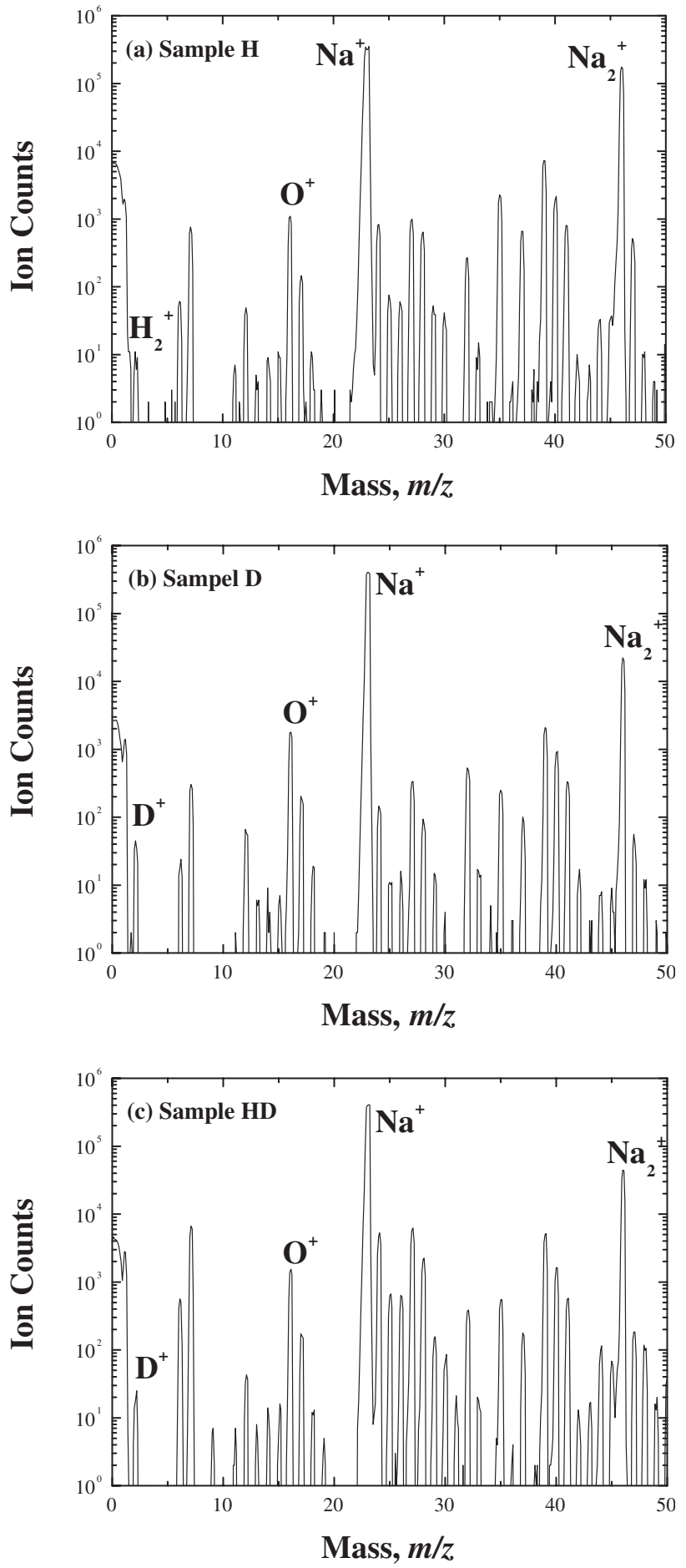

Fig. 4 Narrow mass spectra of positive ions from (a) Sample H, (b) Sample D and (c) Sample HD.

considered to include molecule ions of hydrogen and single ions of deuterium. The relative count of ions of two in mass number to those of one in mass number in Sample D is found to be higher than the in Sample $H$ case. This suggests that hydrogen and deuterium are present in ferric oxyhydroxides formed on these sample surfaces. It is also interesting to note that the relative count of the ions in Sample HD corresponds just between Sample H and Sample HD, as shown in Fig. 4(c).

Similar differences are found in mass spectra of negative ions from Sample H, Sample D and Sample HD, as shown in 
Figs. 5(a), (b) and (c). The relative count of negative ions of two in mass number to those of one in mass number one in Sample D is higher than that for Sample H. Moreover, the relative count of ions of twenty in mass number allocated to $\mathrm{OD}^{-}$to ions of nineteen in mass number attributed to $\mathrm{OH}^{-}$in Sample D is also higher that for Sample H. These results are also used to distinguish between hydrogen and deuterium, although some interference with one from the other is inclined in mass spectra.
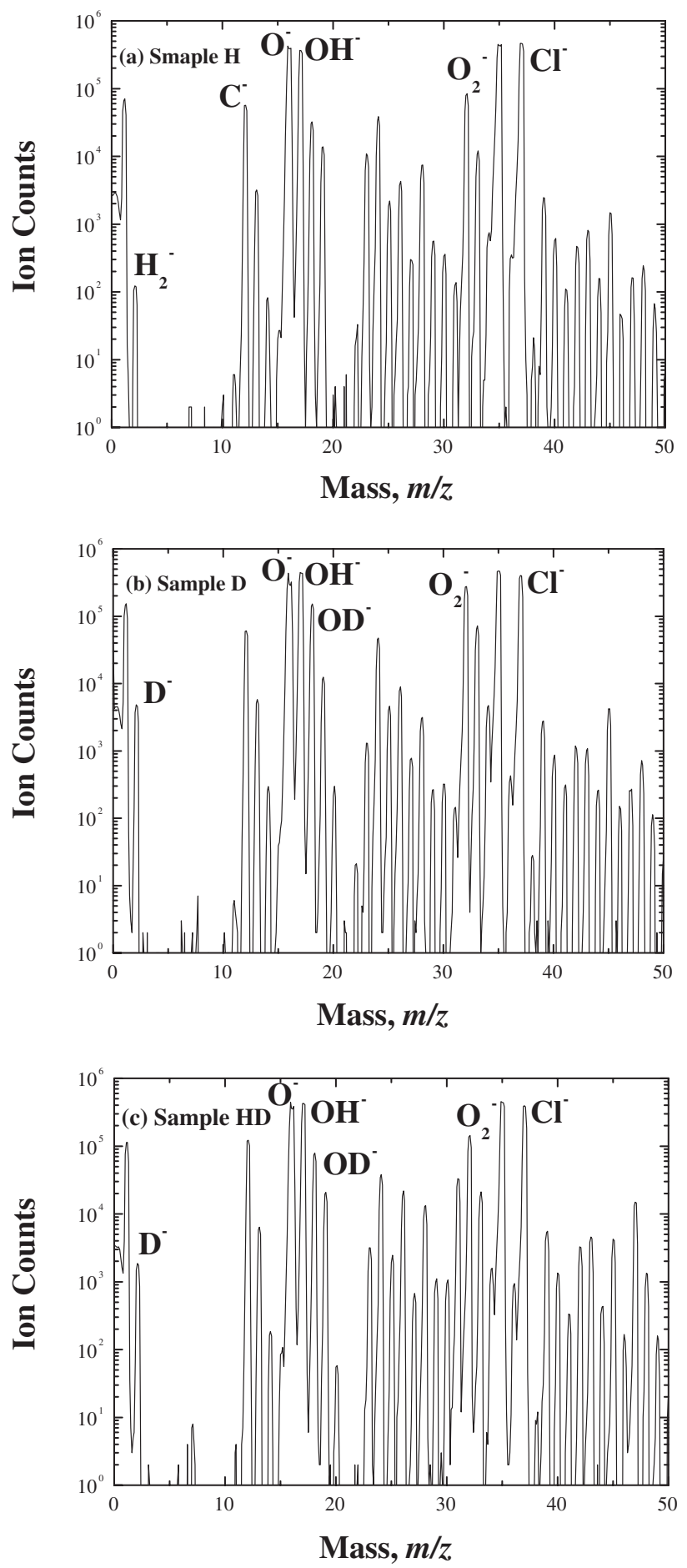

Fig. 5 Narrow mass spectra of negative ions from (a) Sample $\mathrm{H}$, (b) Sample D and (c) Sample HD.

\subsection{Formation process of ferric oxyhydroxides}

Figure 6 summarizes the ratio of counts of deuterium relevant ions to hydrogen relevant ions obtained from Sample H, Sample D and Sample HD. The ratios for Sample D and Sample HD are higher that that of Sample H, although the counts of deuterium relevant ions are less reliable in Sample $\mathrm{H}$ because of an influence of $\mathrm{H}_{2}$. These results indicate that $\mathrm{D}_{2} \mathrm{O}$ dropped in the second operation penetrates into ferric oxyhydroxides formed in the first operation so as to react with the iron substrate, as illustrated in Fig. 7. Such ferric oxyhydroxides formed in the first operation are considered to

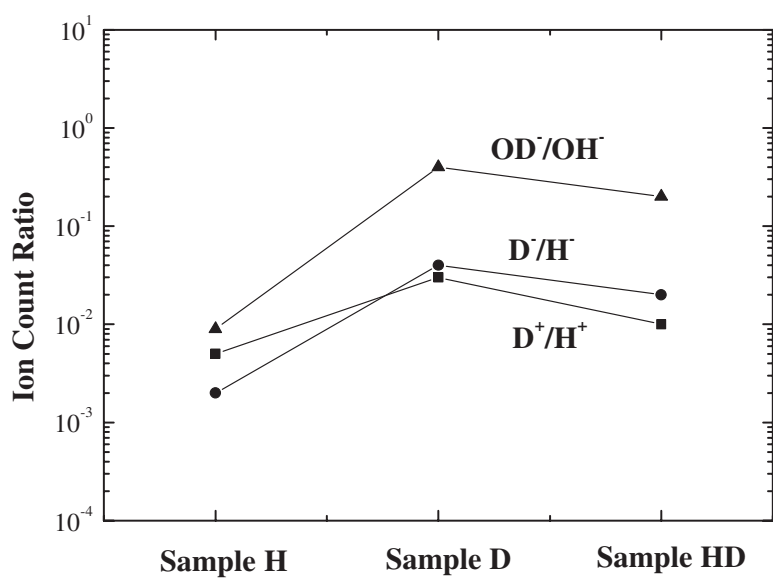

Fig. 6 Ratios of counts of deuterium relevant ions, which are $\mathrm{D}^{+}, \mathrm{D}^{-}$and $\mathrm{OD}^{-}$, and those of hydrogen relevant ions, which are $\mathrm{H}^{+}, \mathrm{H}^{-}$and $\mathrm{OH}^{-}$, for Sample H, Sample D and Sample HD.

(a)

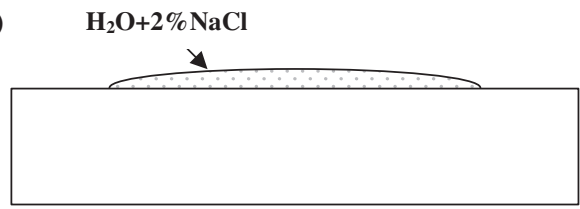

(b)

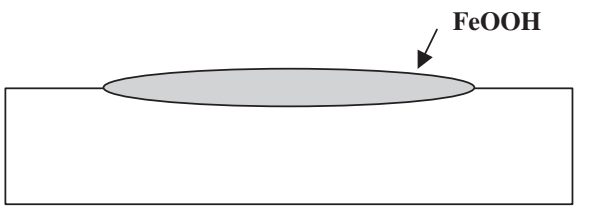

(c)

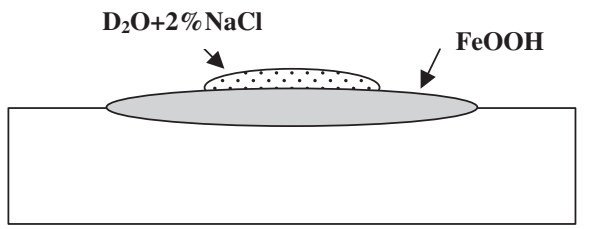

(d)

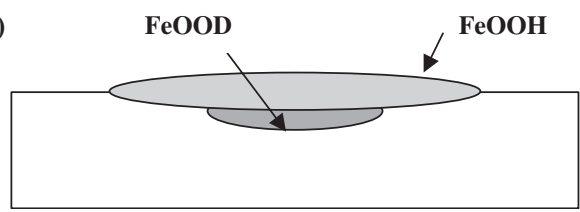

Fig. 7 Schematics representing sequential reactions of the iron substrate with $\mathrm{H}_{2} \mathrm{O}$ and $\mathrm{D}_{2} \mathrm{O}$ containing $\mathrm{NaCl}$. 
be, more or less, porous. It is also noted that the ratio for Sample HD are lower that of Sample D, indicating that the ferric oxyhydroxides formed in the first step operation influence the reaction in the second operation. Since ferric oxyhydroxides can be dissolved in aqueous solution, ${ }^{7)}$ the ferric oxyhydroxides formed in the first operation are likely to be dissolved into $\mathrm{D}_{2} \mathrm{O}$ supplied in the second operation. Then, hydrogen is contained in the reaction front of the ferric oxyhydroxides formed in the second operation. These results provide information on an important factor for controlling a corrosion process of iron, such as the permeability or effective channel of water through ferric oxyhydroxides and the dissolution and precipitation of cations and anions in these processes. For instance, control of atomistic reaction in a surface layer is considered to be important in order to modify the formation or transformation of very fine ferric oxyhydroxides under cyclic reaction conditions.

Finally, let us discuss the origins of hydrogen and deuterium relevant ions in ferric oxyhydroxides form the SIMS measurements. These ions are formed during sputtering the ferric oxyhydroxides by $\mathrm{Cs}^{+}$bombardment. Since the structure of the ferric oxyhydroxides can be described by the network structure of $\mathrm{FeO}_{6}$ octahedral units containing hydrogen, ${ }^{3,8)}$ the bonding between $\mathrm{Fe}$ and $\mathrm{O}$ seems to be relatively strong, as observed in fragment ions of Figs. 1, 2 and 3. This is a reason why hydrogen and deuterium relevant ions are mainly observed as single atom ions of hydrogen and deuterium, and $\mathrm{OH}^{-}$ions, which have a strong affinity with electron. Corrosion products such as ferric oxyhydroxides are considered to originate from ferrous hydroxides, which are typically formed through the following reaction:

$$
\mathrm{Fe}+\mathrm{O}_{2}+2 \mathrm{H}_{2} \mathrm{O} \rightarrow 2 \mathrm{Fe}(\mathrm{OH})_{2} .
$$

The origin of hydrogen in corrosion products is water, in which hydrogen can be labeled by deuterium. On the other hand, oxygen in ferric oxyhydroxides comes from not only water but also dissolved oxygen in water. However, a fraction of such oxygen origins is hardly evaluated, and therefore labeling of oxygen may be less effective in analysis. Nevertheless, careful analysis of mass spectra suggests that deuterium in $\mathrm{D}_{2} \mathrm{O}$ are used as tracers for studying the formation and growth process of ferric oxyhydroxides, which may be well characterized when coupled with the application of an oxygen isotope, for example ${ }^{18} \mathrm{O}$.

\section{Concluding Remarks}

The feasibility of secondary ion mass spectrometry (SIMS) has been made for analyzing hydrogen and deuterium in ferric oxyhydroxides, which is formed by reaction of an iron substrate with water; either $\mathrm{H}_{2} \mathrm{O}$ or $\mathrm{D}_{2} \mathrm{O}$ containing a small amount of sodium chloride. Main concluding remarks drawn from this work are as follows:

(1) Deuterium in ferric oxyhydroxides can be discriminated from the hydrogen case by using $\mathrm{D}^{+}, \mathrm{D}^{-}$and $\mathrm{OD}^{-}$in mass spectra obtained by SIMS.

(2) Mass spectra from an iron sample, which firstly reacted with $\mathrm{H}_{2} \mathrm{O}$ and subsequently was dried and finally reacted with $\mathrm{D}_{2} \mathrm{O}$, indicate that $\mathrm{D}_{2} \mathrm{O}$ is considered to reach a reaction front of the iron substrate through the ferric oxyhydroxides which are formed by reaction with $\mathrm{H}_{2} \mathrm{O}$.

(3) The usefulness of SIMS analysis using isotopes is recognized as a tool for characterizing formation process of ferric oxyhydroxides and permeability of foreign ions in the ferric oxyhydroxides.

\section{Acknowledgements}

The authors are grateful to Mr. T. Sato and Mr. M. Itoh for their help and maintenance of SIMS apparatus.

\section{REFERENCES}

1) P. Kofstad: "High Temperature Corrosion", (Elsevier Applied Science, London, 1988) p. 324-341.

2) S. Suzuki, K. Yanagihara, S. Hayashi and T. Mori: J. Surf. Anal. 5 (1999) 278-281.

3) S. Suzuki, T. Suzuki, M. Kimura, Y. Takagi, K. Shinoda, K. Tohji and Y. Waseda: Appl. Surf. Sci. 169-200 (2001) 109-116.

4) A. Delcorte and P. Bertrand: Inter. J. Mass Spectrometry 184 (1999) 217-231.

5) S. Suzuki, Y. Ishikawa, M. Isshiki and Y. Waseda: Mater. Trans., JIM 38 (1997) 1004-1009.

6) P. Wiliams: Practical Surface Analysis, vol. 2-Ion and Neutral Spectroscopy, D. Briggs and M. P. Seah (ed.), (John Wiley \& Sons, Chichester, 1992) p. $177-228$.

7) R. M. Corrnell and U. Schwertmann: The Iron Oxides, (VHC, Weinheim, 1996) p. 267-310.

8) S. Suzuki, M. Saito, M. Kimura, T. Suzuki, H. Kihira and Y. Waseda: ISIJ Int. 43 (2003) 366-372. 